\title{
Zooplankton patchiness and the associated shoaling response of the temperate reef fish Trachinops taeniatus
}

\author{
Marcus A. Gregson*, David J. Booth \\ Department of Environmental Sciences, University of Technology, Sydney, Westbourne Street, Gore Hill, \\ New South Wales 2065, Australia
}

\begin{abstract}
The grouping behaviour of fishes plays an important role in the success of the group and individual in terms of foraging, reproduction and predator avoidance. The temperate Sydney (Australia) reef fish species Trachinops taeniatus was investigated between February and September 2002 to determine whether there was a relationship between shoal dynamics and zooplankton prey distribution. The diet of T. taeniatus consisted mainly of Copepoda. T. taeniatus shoals were strongly associated with the largest patches of Copepoda, with shoal size increasing as prey density increased. Available Copepoda per fish, however, decreased with shoal size, presenting a possible 'overmatching' foraging situation. The present study suggests there may be an optimum shoal size to achieve maximum prey intake, and that shoal location and size may be linked to the distribution of zooplankton prey.
\end{abstract}

KEY WORDS: Copepods $\cdot$ Foraging $\cdot$ Group dynamics $\cdot$ Hulafish

\section{INTRODUCTION}

Grouping in fishes is common, with approximately 16000 species forming shoals as juveniles and approximately 4000 of these species remaining in shoals throughout their lives (Shaw 1975). Living in a group can benefit fish in many ways. A shoal of fish is typically safer from predation than an individual due to increased corporate vigilance (FitzGerald \& Van Havre 1985) and more effective predator evasion techniques (Pitcher 1986). Fish may also benefit from living in a shoal through increased reproductive success (Balshine et al. 2001), or a reduction in energetic output through hydrodynamic advantages (Weihs 1973, but see Pitcher 1986). One of the major benefits typical of shoal residence is greater foraging success, in terms of finding food patches and actual feeding rates (Olla \& Samet 1974, Pitcher et al. 1982).

Foraging rate and foraging success may be substantially increased when individuals group together to form large aggregations (Pitcher et al. 1982). This may simply be a result of a density-dependent increase in the chances of a shoal member finding a food patch (Krebs 1978). However, the increase in foraging efficiency may also be attributed to higher corporate vigilance that allows animals to lower their individual level of vigilance and spend less time in cover, enabling them to delegate more time to feeding (FitzGerald \& Van Havre 1985). This results in more efficient foraging since some fish are unable to maintain vigilance and feed concurrently (Milinski 1990).

There are, however, costs associated with residing in a shoal. Increased competition for resources such as food and shelter can disadvantage certain individuals, especially smaller fish or fish of a low social status (Booth 1995). Strong competitors may actively select to shoal with competitively weaker conspecifics in order to maximise their own food intake (Metcalfe \& Thomson 1995).

The present study examines how Trachinops taeniatus shoal size and location are influenced by zoo- 
plankton density. The 3 hypotheses are: (1) T. taeniatus diet consists primarily of zooplankton prey. (2) T. taeniatus actively hunt for zooplankton prey; hence, T. taeniatus shoals are predicted to be frequently associated with large aggregations of plankton, while areas without $T$. taeniatus have lower plankton density. (3) Shoal size of T. taeniatus influences the success of locating prey patches; hence, the largest shoals of $T$. taeniatus are predicted to be associated with patches of high plankton density, whilst smaller shoals of $T$. taeniatus are predicted to be associated with less dense plankton aggregations.

\section{MATERIALS AND METHODS}

Study sites. Two sites were selected for sampling: (1) the southern side of Harbord headland within Queenscliff Bay and (2) Shelly Beach within Cabbage Tree Bay (hereafter referred to as Harbord Reef and Shelly Beach, respectively). Both sites are located in the Manly Council district of Sydney, New South Wales, Australia $\left(32^{\circ} 53^{\prime} \mathrm{S}, 151^{\circ} 10^{\prime} \mathrm{E}\right)$, approximately $2.5 \mathrm{~km}$ apart.

Shelly Beach, located within the Cabbage Tree Bay Aquatic Reserve, extends from South Steyne and forms part of the North Head of Port Jackson. Two substantial rocky reefs are present, with the study site located at the northern end of the beach. The majority of sampling took place above a depth of $10 \mathrm{~m}$ as the highest density of fish life was located within this depth (M. A. Gregson pers. obs.).

Harbord Reef forms part of the northern headland of Queenscliff Bay and is subjected to open ocean conditions. Although the maximum depth of Harbord Reef is approximately $15 \mathrm{~m}$, the maximum depth of sampling was $10 \mathrm{~m}$, again where the highest density of Trachinops taeniatus were present (M. A. Gregson pers. obs.).

Study species. The eastern hulafish Trachinops taeniatus Günther 1861 (Plesiopidae) is a small, elongated, temperate reef fish attaining a maximum length of $10 \mathrm{~cm}$ (Hutchins \& Swainston 1986). The family Plesiopidae comprises 7 genera and 20 species, 17 of which are found in Australian waters (Kuiter 1996). T. taeniatus are planktivorous (Hutchins \& Swainston 1986, Kuiter 1996) and are found in large shoals along the east coast of Australia, primarily occupying shallow reefs of New South Wales where they shoal high in the water column in a distinct 'dancing' swimming pattern; hence, the common name 'hulafish'.

Previous research on Trachinops taeniatus has determined the suitability of using this species as an environmental indicator of sewage pollution (Smith \& Suthers 1999); however, we are not aware of any publications addressing the shoaling behaviour of this species.
Assessment of fish shoals and diet. Trachinops taeniatus to be analysed for gut contents were caught over $2 \mathrm{~d}$ from 6 separate shoals, for a total of 20 fish. These fish were immediately euthanased in an ice bath and then preserved in formalin $(10 \%$ mixed with seawater). The guts contained a proportion of unidentifiable macerated prey. To determine the relative importance of various prey items, the identifiable prey items were assigned a percentage value of the total identifiable prey items in the gut. This was done using a simple grid structure on a petri dish, onto which the gut contents were emptied.

Plankton distribution. In order to investigate links between Trachinops taeniatus shoals and zooplankton, the spatial distribution of zooplankton was measured at Shelly Beach and Harbord Reef. Plankton tows were carried out during August and September 2002, with additional sampling in August 2004. Plankton were sampled using SCUBA in a series of 3 tows for each $T$. taeniatus shoal, with each tow at a different depth to allow analyses of abundance as well as vertical stratification of plankton. The 3 tows were made above the $T$. taeniatus shoal, as well as through the middle of a shoal, and also below the shoal, just above the substrate. Therefore, in our sample numbers, each 'tow' referred to actually comprises a series of 3 tows.

An approximately equal number of plankton tows were completed in the morning (06:00 to 09:00 $\mathrm{h}, \mathrm{n}=$ $16)$, midday (09:00 to $13: 00 \mathrm{~h}, \mathrm{n}=16)$, and afternoon (13:00 to $17: 00 h, n=18)$ to randomise the effects of time of day and tide. Very few plankton tows were completed each day so that shoals could be monitored, preventing the same shoal being sampled more than once. Sampling was done at both Shelly Beach and Harbord Reef, but because of the aquatic reserve status of Shelly Beach, Harbord Reef was sampled more often $(\sim 70 \%$ of total samples).

A plankton net of $40 \mathrm{~cm}$ diameter and $250 \mu \mathrm{m}$ mesh was used, with the plankton tow carried out over a $10 \mathrm{~m}$ distance. The maximum depth of plankton tows at both Shelly Beach and Harbord Reef was approximately $10 \mathrm{~m}$. The order of sampling depth was randomised after each series, to account for disturbance of the plankton that may occur while sampling. To deploy the net, 1 diver carefully brought it around the edge of the shoal while a second diver pivoted the retrieval line to the desired sampling height and tow distance. The second diver could then retrieve the net to collect plankton. This technique was used since it had minimal disturbance on the water column prior to sampling and hence was considered not to interfere with the zooplankton population until the actual tow had begun.

Tows were carried out both within a Trachinops taeniatus shoal and in the absence of a shoal. When a tow 
was completed in the absence of a T. taeniatus shoal, the depth towed was similar to that of the preceding sample, ensuring that the depth of sampling in the absence of fish remained random.

Plankton samples were sieved in situ into a specimen jar and preserved in Lugol's solution. Plankton were processed within 1 mo of collection to prevent decomposition. Each plankton tow had five $14 \mathrm{ml}$ aliquots removed from the sample jar, representing approximately $14 \%$ of the total volume collected (sample jar = $500 \mathrm{ml}$ ). The sample jar was thoroughly mixed in between the removal of aliquots. The plankton in these aliquots were counted and identified to class level under light microscopy using a Bogarov chamber.

Trachinops taeniatus shoals were categorised according to the number of fish counted in the shoal immediately prior to plankton sampling. Plankton aggregations were sampled in $T$. taeniatus shoal categories of 0 (no fish present), 1-100 (inclusive), 101-200, 201-300, 301-400, 401-500, 501-600, 601-700 and 701-800. Because of differences in the frequency of shoals in each size category, an equal number of plankton tow replicates for each shoal size was not completed. However, all shoal categories (with the exception of the 401-500 category) had at least 3 plankton tows carried out. The sample numbers for each of the shoal size categories (indicated within parentheses) were: 20 (0 T. taeniatus), 3 (1-100), 6 (101-200), 3 (201-300), 4 (301-400), 0 (401-500), 5 (501-600), 4 (601-700) and 5 (701-800).

Trachinops taeniatus shoal size was estimated by carrying out 2 separate counts of the shoal by a single observer (M. A. Gregson), who was either stationary or swimming around the shoal depending on its size. A pilot study used video recordings of shoals to compare estimates made by the observer in the water using 2 or 5 counts of the shoal with the actual number of fish assessed using the recorded footage. The results indicated that there was no significant difference in precision (ANOVA; $\mathrm{n}=18, F=5.12, \mathrm{df}=1, \mathrm{p}=0.12$ ) using either 2 or 5 counts of a shoal. Therefore, only 2 estimates were made when calculating shoal size, with the mean of the 2 counts used in final analyses.

Analyses. Analyses of plankton were only based on Copepoda numbers since they were the dominant plankton in the tows (>95\%). In addition, Copepoda was the only zooplankton analysed since it made up a significant proportion of prey items found in Trachinops taeniatus guts (see 'Results').

Gut content data were not normally distributed and could not be normalised through transformation; hence, they were analysed using Kruskal-Wallis tests, with probability values adjusted for ties.

The plankton analyses involved calculating the mean Copepoda density amongst various shoal sizes as well as mean Copepoda density per fish in a shoal. Plankton counts consisted of the sum of the 5 Bogarov chamber samples for each stratification level of the plankton tow, adjusted for the volume that the 5 aliquots represented from the total sample. The plankton tow volume was $1.26 \mathrm{~m}^{3}$; however, the plankton count was converted to represent plankton per $\mathrm{m}^{3}$. The data were log-transformed for normalisation. A Kolmogorov-Smirnov test for normality showed the data to be normalised following this process $(\mathrm{p}=0.200)$.

To calculate the mean Copepoda density per fish, the plankton counts for each shoal size category were totalled and divided by the total number of fish present in the sampled shoals. This gave a value of Copepoda available per resident fish.

The Kolmogorov-Smirnov tests as well as ANOVA, $t$-tests and Kruskal-Wallis tests were carried out using the Minitab (1998) statistics package. Tukey's post hoc test was also carried out with Minitab (1998) following all ANOVA. Figures shown in the 'Results' are illustrated with letters above treatment groups to indicate whether groups were statistically similar (indicated by the same letter), or statistically dissimilar (indicated by the use of different letters), as determined by Tukey's post hoc tests.

\section{RESULTS}

A large proportion of the identifiable prey items within Trachinops taeniatus guts consisted of the class Copepoda, either intact or as identifiable segments or somites. Other significant prey items found were Bivalvia larvae, with very few malacostracans (euphausids), dinoflagellates and polychaetes found. As a percentage of the identifiable gut contents, Copepoda made up approximately $60 \%$, a significantly larger proportion than other prey items such as Polychaeta $(<1 \%)$, Malacostraca $(<1 \%)$ and Bivalvia $(\sim 40 \%)$ (Kruskal-Wallis test: $\mathrm{n}=20, H=66.96, \mathrm{df}=3, \mathrm{p}<$ 0.001).

Plankton counts from Harbord Reef and Shelly Beach were combined since it was determined that there was no significant difference in overall plankton abundance ( $t$-test; $t=2.14, \mathrm{df}=1, \mathrm{p}=0.238$ ) or vertical distribution (ANOVA: $F=2.03, \mathrm{df}=2, \mathrm{p}=0.318$ ), between the 2 locations.

Copepoda density was significantly higher in areas where Trachinops taeniatus were present compared to areas of T. taeniatus absence (Table 1). Copepoda density at the shallowest depth (above the $T$. taeniatus shoal) was significantly higher than the deepest tow (beneath the T. taeniatus shoal), in both the presence and absence of a T. taeniatus shoal (2-factor ANOVA: $p<0.001$; Fig. 1, Table 1). There was no interaction 


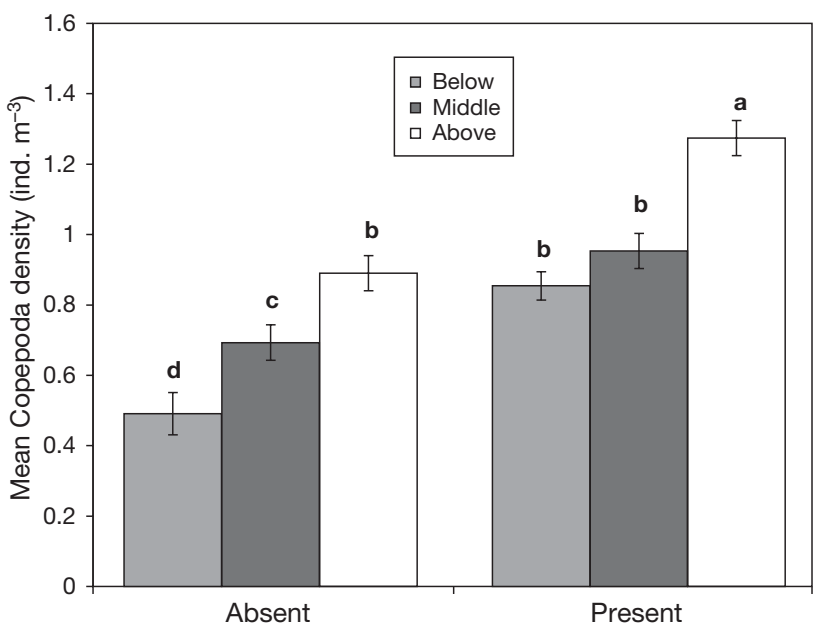

Fig. 1. Stratification of Copepoda in both the presence and absence of Trachinops taeniatus shoals ( $\mathrm{n}=20$ absent, 20 present; $\mathrm{n}=40$ below, 40 middle, 40 above. 2-factor ANOVA, data $\log _{10}$-transformed. Vertical bars are \pm SEM. Letters above bars differentiate between statistically similar results determined by Tukey's post hoc tests, CI < 0.05)

effect between vertical distribution and the presence/ absence of a T. taeniatus shoal.

There were significant differences in Copepoda density between shoal size categories. Shoal sizes of 601 to 700 individuals were associated with significantly higher densities of Copepoda than all other shoal size categories (ANOVA: $\mathrm{n}=50, F=23.11$, $\mathrm{df}=7, \mathrm{p}<0.001$, Fig. 2). In addition, the largest 3 shoal sizes had a significantly higher Copepoda density than the other 5 smaller shoal size categories (Fig. 2).

The ratio of Copepoda per fish varied significantly between the shoal sizes of Trachinops taeniatus. There appeared to be a negative relationship, with the smaller shoal sizes being associated with the largest proportion of Copepoda (Fig. 3). Shoal sizes of 1 to 100 individuals had the highest density of Copepoda per fish (ANOVA: $\mathrm{n}=30, F=16.38$, df =6, p < 0.001; Fig. 3).

Table 1. Trachinops taeniatus. Results of 2-factor ANOVA comparing vertical distribution of Copepoda in the presence or absence of $T$. taeniatus shoals. ( $\mathrm{n}=20$ absent, 20 present; $\mathrm{n}=40$ below, 40 middle, 40 above; data were $\log _{10}$-transformed)

\begin{tabular}{|c|c|c|c|c|c|c|c|}
\hline Source & df & & Mean & & SS & $F$ & $\mathrm{p}$ \\
\hline $\begin{array}{l}\text { Vertical } \\
\text { distribution }\end{array}$ & 2 & $\begin{array}{c}\text { Below } \\
0.67\end{array}$ & $\begin{array}{c}\text { Middle } \\
0.84\end{array}$ & $\begin{array}{c}\text { Above } \\
1.07\end{array}$ & 7.21 & 46.22 & $<0.001$ \\
\hline $\begin{array}{l}\text { Presence or } \\
\text { absence }\end{array}$ & 1 & $\begin{array}{c}\text { Absent } \\
0.68\end{array}$ & $\begin{array}{c}\text { Present } \\
1.04\end{array}$ & & 10.83 & 105.93 & $<0.001$ \\
\hline Interaction & 2 & & & & 0.27 & 1.93 & 0.23 \\
\hline Error & 270 & & & & 32.64 & & \\
\hline Total & 275 & & & & 50.95 & & \\
\hline
\end{tabular}

\section{DISCUSSION}

The gut contents of Trachinops taeniatus consisted mostly of Copepoda somites, indicating the high importance of copepods in the diet of $T$. taeniatus. However, the importance of copepods may have been underestimated in this study because of the inability to identify the macerated items in the gut.

Reef locations that were inhabited by Trachinops taeniatus were associated with larger densities of Copepoda (Fig. 1, Table 1), suggesting that T. taeniatus shoals exploit or target larger food patches. Furthermore, higher Copepoda densities were associated with larger T. taeniatus shoals (Fig. 2), although Copepoda density per fish was negatively related to shoal size (Fig. 3). This suggests that there is perhaps an optimum shoal size in which to reside to maximise prey intake. The presence of a $T$. taeniatus shoal did not alter the vertical distribution of Copepoda (Fig. 1, Table 1), suggesting that the correlation between shoal size and Copepoda density is not due to a third contributing variable such as shelter or current.

Shoal size was positively related to Copepoda density (Fig. 2), and there are at least 4 possible explanations for this result. First, large shoals may be adaptive in many fish species due to an increased foraging success (Street \& Hart 1985, Baird et al. 1991). Similarly, larger shoal sizes of Trachinops taeniatus may increase foraging success in terms of locating larger plankton patches, since the search rate among the shoal increases with each fish that joins (Pitcher et al. 1982). As well as the disadvantage of a reduced total searching ability within a small shoal, individual T. taeniatus in smaller shoals also swim closer together (M. A. Gregson unpubl. data) further reducing their ability to locate aggregations of plankton. This may explain why smaller shoals of $T$. taeniatus were found in smaller patches of Copepoda (Fig. 2).

Second, there may have been higher Copepoda densities at larger shoal sizes because a larger group inhibits feeding rate so that plankton would not be depleted as rapidly. This is unlikely, however, as numerous researchers have found that the increase in corporate predator awareness associated with a larger shoal results in a lowered level of individual predator awareness, consequently enabling an improved rate of food consumption (e.g. Magurran \& Pitcher 1983, Morgan 1988). A negative densitydependent feeding rate is, therefore, not a likely explanation for the result found.

Third, there may be a non-adaptive reason for the high density of Copepoda found at large shoal sizes. A Trachinops taeniatus 
Fig. 2. Mean Copepoda density adjacent to various sizes of Trachinops taeniatus shoals. Control group of 0 shoal size (fish absent) is also included. No samples were collected in the 401-500 shoal size category. $\mathrm{n}=20(0 \mathrm{~T}$. taeniatus), 3 (1-100), 6 (101-200), 3 $(201-300), 4$ (301-400), 0 (401$500), 5(501-600), 4(601-700), 5$ (701-800). ANOVA: data $\log _{10^{-}}$ transformed. Vertical bars are \pm SEM. Letters above bars differentiate between statistically similar results determined by Tukey's post hoc tests, CI $<0.05$
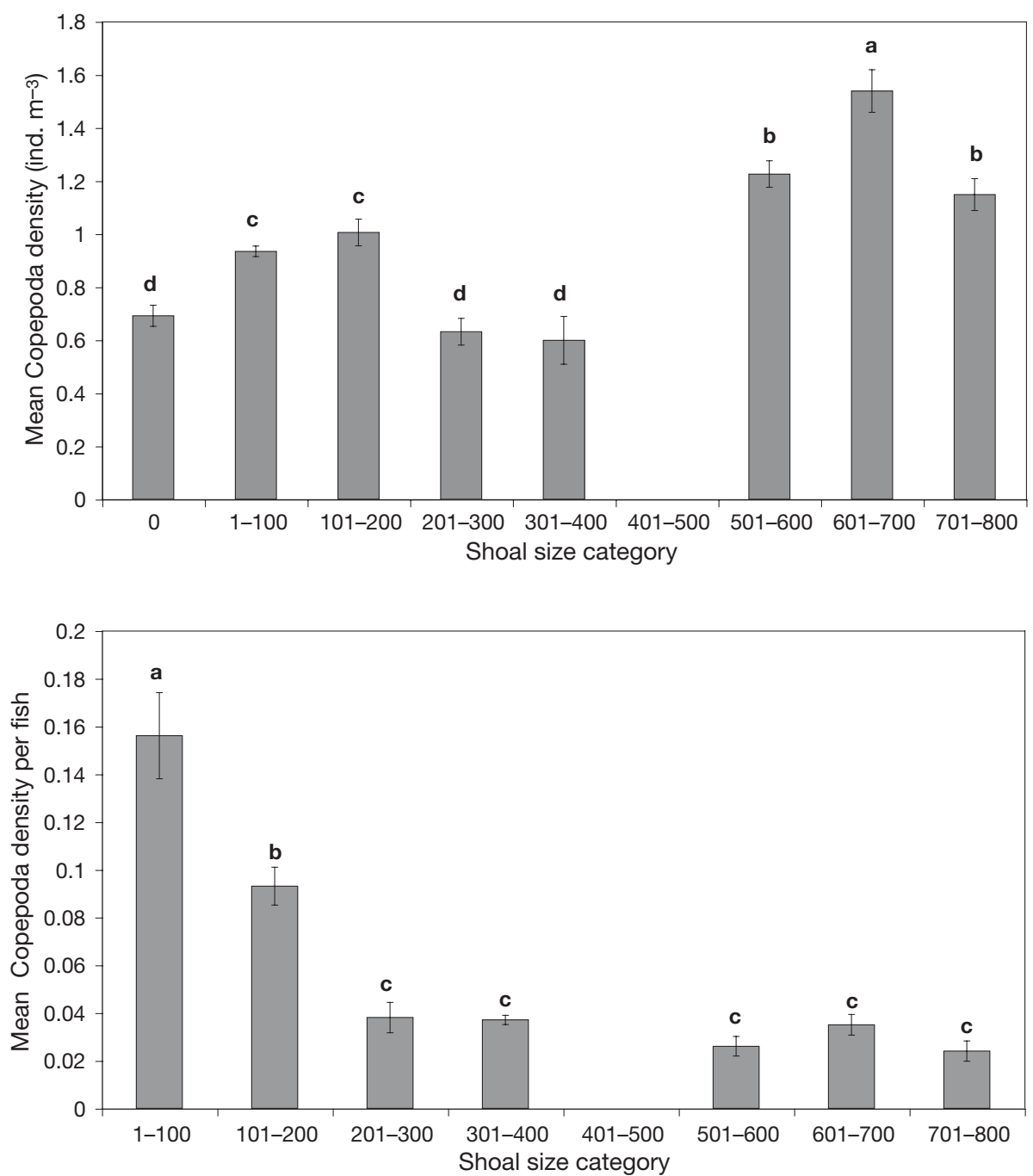

Fig. 3. Mean plankton count per fish within various sized Trachinops taeniatus shoals. $\mathrm{n}=3$ (1-100 T. taeniatus), 6 (101-200), $3(201-300), 4(301-400), 0$ (401$500), 5$ (501-600), 4 (601-700), 5 (701-800). ANOVA: data $\log _{10^{-}}$ transformed. Vertical bars are \pm SEM. Letters above bars differentiate between statistically similar results determined by Tukey's post hoc tests, CI $<0.05$

individual, or small shoal, may simply locate an abundant food patch and form an aggregation in that area. A number of individuals may then be attracted to that area through behavioural cues, hence forming a large aggregation (Shulman 1985, Krause 1992).

There may also be a fourth explanation for these results, which does not assume any relationship between Trachinops taeniatus and Copepoda, whereby fish and plankton coincide due to abiotic factors. Although these taxa may have similar preferences for environmental factors such as water temperature and be affected similarly by local eddies, determining whether the species exist in mutual exclusion would require very difficult manipulative experiments. The strong association of $T$. taeniatus with plankton (Fig. 1), and the gut content evidence suggest that T. taeniatus actively target the Copepoda aggregations as a food source, rather than plankton and fish being located together due to other extraneous factors.
Therefore, the probable reason for shoal size positively related with Copepoda is due to an increased foraging ability in a large shoal, as well as a simple cumulative effect of fish observing and joining other fish when they locate a profitable food patch.

Areas of Trachinops taeniatus absence coincided with fewer Copepoda (Fig. 1), suggesting that T. taeniatus ignored or vacated unprofitable plankton patches. Numerous authors have documented the preference that test fish display for more profitable patches (Croy \& Hughes 1991, Krause 1992). A few key models have been established that address the question of the best time to leave an unprofitable food patch (Krebs et al. 1974, Charnov 1976, McNair 1982). Unfortunately, most of these theories have not yet been applied to an ichthyological situation because of the group foraging behaviour of many species. This behaviour means that individuals are subject to other, more complex influences, such as the competitive 
actions of shoalmates. Furthermore, individual energy budgets and the relative safety of the shoal in which a fish resides can also affect the decision of when to leave a shoal (Krause 1993, Sogard \& Olla 1997). Further study into the complex individual behaviour and competition within a $T$. taeniatus shoal is needed to accurately predict the optimal time when a fish in a shoal should leave a food patch.

Although shoal size increased with Copepoda density (Fig. 2), there was a significant negative relationship between Copepoda per fish and shoal size (Fig. 3). There may, therefore, exist an ideal shoal size that maximises plankton availability. From our results, it appears that residence in a shoal size of 1 to 100 fish maximises available Copepoda per fish (Fig. 3). The results also suggest that fish in larger shoals are not able to accurately determine a patch of maximum available prey. More likely, however, is that these fish offset the disadvantage of reduced Copepoda availability by residing in a larger and safer shoal, with large shoals a priority especially when predators are present (Krause \& Godin 1994). Laboratory experiments have shown that satiated fish will tend to reside in large, safe shoals even when they receive less food per fish. Hungry fish, however, will tend to reside in smaller or otherwise less safe shoals, increasing their share of available food items (Croy \& Hughes 1991, Krause 1993). It may be possible that a determining factor of Trachinops taeniatus shoal size is the hunger level of the fish.

Sibly (1983) suggests that the theoretical optimum group size is not met in the wild, since groups of this 'optimal' size are unstable. This is due to animals obtaining greater average fitness benefits from a group than as individuals. Hence, shoal sizes are hypothesised to be larger than the optimum, creating an 'average zero net benefit' situation, where the safety of a larger shoal offsets the disadvantage of reduced food items per fish (Pitcher 1986). This may explain the low numbers of Copepoda available per fish in the large shoals of Trachinops taeniatus (Fig. 3), as fish may be joining these larger groups primarily for safety, depleting any available plankton. It may, therefore, be important to consider other factors such as safety and reproductive advantages of a shoal, rather than foraging benefits alone, as to what constitutes the ideal shoal size.

It should be considered that the dynamic nature of fish aggregation means that a shoal can form and disperse rapidly. The number of shoals in an area can vary through the day as well as between day and night (Fréon et al. 1996). This has implications for sampling since we are unable to tell how long a shoal has been formed and whether shoal size has recently changed. It is therefore difficult to determine whether, for example, a small shoal was formed as a small shoal, or whether a larger aggregation has dispersed following decimation of a plankton patch. Estimations of Copepoda density per fish can, therefore, only be valid for that point in space and time, since shoals may diminish prey patches and disperse quickly.

Further work in the fields already discussed would greatly benefit the understanding of Trachinops taeniatus shoaling behaviour. Examining actual foraging rate and success within varying $T$. taeniatus shoal sizes, although difficult, may help to explain the difference in Copepoda densities measured. Measuring competitive ability within and between shoals may also help to explain why $T$. taeniatus shoals appeared not to maximise their potential plankton intake in some shoal size categories.

Acknowledgements. This work was generously supported by the University of Technology Sydney, Department of Environmental Sciences. Many thanks to E. Buckle for assistance in the field and during manuscript preparation. Thanks also to the anonymous referees whose constructive criticism greatly improved this manuscript.

\section{LITERATURE CITED}

Baird TA, Ryer CH, Olla BL (1991) Social enhancement of foraging on an ephemeral food source in juvenile walleye pollock, Theragra chalcogramma. Environ Biol Fish 31: 307-311

Balshine S, Leach B, Neat F, Reid H, Taborsky M, Werner N (2001) Correlates of group size in a cooperatively breeding cichlid fish (Neolamprologus pulcher). Behav Ecol Sociobiol 50:134-140

Booth DJ (1995) Juvenile groups in a coral-reef damselfish: density-dependent effects on individual fitness and population demography. Ecology 76:91-106

Charnov EL (1976) Optimal foraging: the marginal value theorem. Theor Popul Biol 9:129-136

Croy MI, Hughes RN (1991) Effects of food supply, danger and competition on choice of foraging location by the fifteen-spined stickleback, Spinachia spinachia L. Anim Behav 42:131-139

FitzGerald GJ, Van Havre N (1985) Flight, fright and shoaling in sticklebacks (Gasterosteidae). Biol Behav 10: 321-331

Fréon P, Gerlotto F, Soria M (1996) Diel variability of school structure with special reference to transition periods. ICES J Mar Sci 53:459-464

Hutchins B, Swainston R (1986) Sea fishes of southern Australia. Swainston Publishing, Perth

Krause J (1992) Ideal free distribution and the mechanism of patch profitability assessment in three-spined sticklebacks (Gasterosteus aculeatus). Behaviour 123:27-37

Krause J (1993) The influence of hunger on shoal size choice by three-spined sticklebacks, Gasterosteus aculeatus. J Fish Biol 43:775-780

Krause J, Godin JG (1994) Shoal choice in the banded killifish (Fundulus diaphanus, Teleostei, Cyprinodontidae): effects of predation risk, fish size, species composition and size of shoals. Ethology 98:128-136 
Krebs JR (1978) Optimal foraging: decision rules for predators. In: Krebs JR, Davies NB (eds) Behavioural ecology: an evolutionary approach. Blackwell Science, Oxford, p 23-63

Krebs JR, Ryan JC, Charnov EL (1974) Hunting by expectation or optimal foraging? A study of patch use by chickadees. Anim Behav 22:953-964

Kuiter RH (1996) Guide to sea fishes of Australia. New Holland, Sydney

Magurran AE, Pitcher TJ (1983) Foraging, timidity and shoal size in minnows and goldfish. Behav Ecol Sociobiol 12: $147-152$

McNair JN (1982) Optimal giving up time and the marginal value theorem. Am Nat 119:511-529

Metcalfe NB, Thomson BC (1995) Fish recognize and prefer to shoal with poor competitors. Proc R Soc Lond Ser B 259: 207-210

Milinski M (1990) No alternative to tit-for-tat cooperation in sticklebacks. Anim Behav 39:989-991

Minitab (1998) Mintab for Windows-Student Edition v.12. Addison-Wesley, New York

Morgan MJ (1988) The influence of hunger, shoal size, and predator presence on foraging in bluntnose minnows. Anim Behav 36:1317-1322

Olla BL, Samet C (1974) Fish-to-fish attraction and the facilitation of feeding behaviour is mediated by visual stimuli in

Editorial responsibility: Otto Kinne (Editor-in-Chief), Oldendorf/Luhe, Germany striped mullet, Mugil cephalus. J Fish Res Board Can 31: 1621-1630

Pitcher TJ (1986) Functions of shoaling behaviour in teleosts. In: Pitcher TJ (ed) Behaviour of teleost fishes. Johns Hopkins University Press, Baltimore, p 294-337

Pitcher TJ, Magurran AE, Winfield I (1982) Fish in larger shoals find food faster. Behav Ecol Sociobiol 10:149-151

Shaw E (1975) Fish in schools. Nat Hist 84:40-46

Shulman M (1985) Recruitment of coral reef fishes: effects of distribution of predators and shelter. Ecology 66: 1056-1066

Sibly RM (1983) Optical group size is unstable. Anim Behav 31:947-948

Smith AK, Suthers IM (1999) Effects of sewage effluent discharge on the abundance, condition and mortality of hulafish, Trachinops taeniatus (Plesiopidae). Environ Pollut 106:97-106

Sogard SM, Olla BL (1997) The influence of hunger and predation risk on group cohesion in a pelagic fish, walleye pollock Theragra chalcogramma. Environ Biol Fish 50: 405-413

Street NG, Hart PJB (1985) Group size and patch location by the stoneloach, Noemacheilus barbatulus, a non-visually foraging predator. J Fish Biol 217:785-792

Weihs D (1973) Hydromechanics and fish schooling. Nature 241:290-291

Submitted: October 9, 2003; Accepted: April 19, 2005

Proofs received from author(s): August 17, 2005 